\title{
Fear-motivated vicious-circle behavior maintained through secondary punishment
}

\author{
KENNETH B. MELVIN, THOMAS K. IRVING, and STEVEN PRENTICE-DUNN \\ University of Alabama, University, Alabama 35486
}

\begin{abstract}
Two experiments attempted to establish vicious-circle behavior through fear motivation combined with secondary punishment. In Experiment 1, rats were trained with two CSs, a tone and a buzzer, paired with shock in different contexts. Secondary punishment based on delay and trace conditioning procedures facilitated running in fear-motivated rats, relative to four control groups. In Experiment 2, rats were given pairings of a tone CS with shock, and a buzzer CS with a drop into a water tank. Fear-motivated rats which received secondary punishment during either $33 \%$ or $100 \%$ of test trials exhibited self-punitive running relative to a nonpunished (0\%) group and a backward-conditioning control group. Results indicate that "all secondary" vicious-circle behavior can be established through Pavlovian conditioning, thus supporting a conditioned fear interpretation.
\end{abstract}

Following the definitive study by Brown, Martin, and Morrow (1964), a number of experimenters have reproduced the vicious-circle phenomenon (see reviews by Brown, 1969; Melvin, 1971). Typically, vicious-circle behavior is established by training rats to escape (or avoid) shock administered in both the startbox and alley segments of a runway. Shock is terminated by entering a shock-free goalbox. During "extinction," shock is delivered somewhere in the alley; the startbox is now "safe." The subjects so treated exhibit self-punitive behavior. They leave the safe startbox and take punishment in the alley. Relative to controls receiving no punishment in the apparatus, punished subjects yield faster running speeds and are slower to extinguish.

An influential theoretical interpretation of this behavior is the Mowrer-Brown hypothesis (Brown, 1969; Melvin \& Martin, 1966). According to this explanation, during extinction the subject leaves the safe start area because of conditioned fear. The resulting punishment maintains this fear, which generalizes throughout the homogeneous runway. The instrumental response is reinforced by fear reduction and, in most cases, pain reduction.

While most research on the vicious-circle phenomenon has involved the use of electric shock, several investigators have attempted a more direct test of the

This research was supported by the University Research Committee of The University of Alabama (Project 901). These data were reported at The Psychonomic Society meeting in Washington, D.C., November 1977. We wish to express our appreciation to Alexis Artwohl for running half of the subjects in Experiment 1 and to Paul S. Siegel for his helpful comments. Requests for reprints should be sent to Kenneth B. Melvin, Department of Psychology, Box 2968, University of Alabama, University, Alabama 35486. conditioned fear assumption. Melvin and Stenmark (1968) gave rats paired presentations of a buzzer and shock. Following this conditioning phase, the animals learned to escape the buzzer CS by traversing an alley. Subsequently, shock-punished animals showed faster speeds and more stable performances than a nonpunished group. In a similar paradigm, Galvani (1969) found that seslf-punitive behavior was an increasing function of the number of CS-UCS pairings. Further, Kruger (1974) found that self-punitive running increased as a function of UCS intensity during initial classical conditioning.

These experimenters examined a secondarily motivated running response. Another approach has been through the use of secondary punishment. In 1969, Bender demonstrated vicious-circle behavior in rats by using a buzzer (which had previously been paired with shock) as the punishment. This secondary punishment was given during the extinction of an avoidance response. Saunders (1974) replicated and extended Bender's results. Vicious-circle behavior through secondary punishment was also found with mice (Brister, Note 1) and humans (Miller, House, \& Melvin, 1978). These experimenters also used an avoidance-training paradigm.

While earlier research certainly indicates that fear plays a role in vicious-circle behavior, all experiments have involved shock somewhere during the instrumental response sequence. In the present experiments, shock-elicited running was eliminated from all aspects of the vicious-circle paradigm. The motivation to respond as well as the punishment of the response was secondary, i.e., they depended upon conditioned fear. Our intentions were to demonstrate such "allsecondary" vicious-circle behavior and examine variables which might influence it. 


\section{EXPERIMENT 1}

The first experiment attempted to induce selfpunitive running through Pavlovian conditioning. Two CSs, a buzzer and a tone, were paired with shock in different contexts. As rats learned a new response to terminate the tone CS, appropriate groups were secondarily punished with the buzzer CS. A traceconditioning procedure was examined along with a standard delay-conditioning procedure, as was the effect of the tone without prior pairings with shock.

\section{Subjects \\ Method \\ The subjects were 42 naive male Long-Evans hooded rats obtained from Charles River Breeding Lab, Inc. They ranged in age from 90 to 135 days at the start of the experiment. Each rat was handled briefly and caged individually 2 to 5 days prior to testing.}

\begin{abstract}
Apparatus
Major components of the apparatus were a straight runway and a portable conditioning chamber. The runway consisted of a $1-\mathrm{ft}$ $(30.5-\mathrm{cm})$ startbox, a $4-\mathrm{ft}(122-\mathrm{cm})$ alley, and a black wooden goalbox. It has been described in detail by Melvin, Athey, and Heasley (1965). The goalbox measured 12 in. long $\times 10$ in. wide $\times 10$ in. high $(30.5 \times 25.1 \times 25.1 \mathrm{~cm})$. The white startbox and alley had grid floors, glass lids, and were 4 in. $(10.2 \mathrm{~cm})$ wide and $10 \mathrm{in}$. $(25.1 \mathrm{~cm})$ high. In addition, the startbox was divided into upper and lower compartments by a trapdoor, hinged along one edge 6 in. $(15.3 \mathrm{~cm})$ above the grid. A barrier prevented the subject from leaving the upper compartment; a guillotine door at the entrance of the goalbox prevented retracing. The tone was presented through a speaker mounted in the center of the back wall of the upper compartment of the startbox; the 76-dB buzzer was located .5 in. $(1.3 \mathrm{~cm})$ from the back of the startbox and $2 \mathrm{ft}(61 \mathrm{~cm})$ from the conditioning chambers. The conditioning chamber was composed of Plexiglas sides, a Masonite door at each end, and a screened roof; it measured $81 / 2 \times 31 / 2 \times 4$ in. $(21.7 \times 8.9 \times 10.2 \mathrm{~cm})$. Two galvanized iron plates, each $71 / 2 \times 1 \frac{1}{2}$ in. $(19.1 \times 3.8 \mathrm{~cm})$ and $1 / 2$ in. $(1.3 \mathrm{~cm})$ apart, formed the floor.

Photocells and associated electronic equipment recorded response times to $.01 \mathrm{sec}$. Prepunishment time was defined as the time which elapsed from the release of the startbox trapdoor until interruption of a light beam located $24.5 \mathrm{in} .(62.3 \mathrm{~cm})$ from the rear wall of the startbox. Alley time was measured from the interruption of a light beam $12.5 \mathrm{in.}(31.8 \mathrm{~cm})$ from the back wall of the startbox to the interruption of a second light beam .5 in. $(1.3 \mathrm{~cm})$ inside the goalbox. Shock intensity was governed by a Powerstat, electricity being delivered through a $10-\mathrm{k} \Omega$ series resistor and monitored with a vacuum-tube ac voltmeter.
\end{abstract}

\section{Procedure}

The experiment was run in three phases. In Phase 1, the animals were placed in the conditioning chamber and given nine presentations of a buzzer and a shock. The temporal arrangement of these two stimuli for a specific rat depended on group assignment. During Phase 2, the rats were given nine tone-shock pairings, except for subjects in Groups TC-NPC and TC-SP. These subjects also received nine presentations of the tone; however, the shock was omitted. In Phase 3 (testing), the rats performed the instrumental response of traversing a runway. Some rats ran to escape the secondarily aversive tone.

Some rats were also given secondary punishment, i.e., the buzzer. Table 1 illustrates the experimental design. Details of the procedure for each phase are given below.

Phase 1: Fear conditioning-buzzer. On Day 1, the subject was handled and then placed in the conditioning chamber for $10 \mathrm{~min}$ immediately prior to the beginning of the conditioning period. Each subject was assigned randomly to one of four groups ( $n=8 /$ group) -CS-SP, CS-NPC, CS-TSP, or CS-RBC-or, on five of the replications, to one of the two supplementary control groups ( $\mathrm{n}=$ 5/group)-TC-NPC and TC-SP.

For the CS-SP, CS-NPC, TC-SP, and TC-NPC groups, on Trial 1 the experimenter initiated a 3-sec buzzer (CS) which terminated simultaneously with the onset of a $1-\sec 65-\mathrm{V}$ ac shock (US). Subjects received eight additional CS-US pairings spaced at intervals of $195 \mathrm{sec}$.

As Table 1 indicates, the remaining two groups were treated in an identical manner to those above, except for the following modifications. Trace-conditioned group: On all nine trials, the rat received the 3-sec buzzer CS; however, the onset of the 1-sec shock occurred $12 \mathrm{sec}$ after buzzer onset. Random-buzzer group: Here, nine shocks were presented at 195 -sec intervals. On each trial, the buzzer appeared randomly within one of five possible intervals of $39 \mathrm{sec}$ following shock termination on the preceding trial. Thus, the US-US interval was constant, while the buzzer-US interval was variable.

Phase 2: Fear conditioning - tone. Twenty-two to $25 \mathrm{~h}$ following Phase 1 , the subject was placed in the goalbox. The guillotine door was opened, allowing the subject to explore the goalbox, runway, and startbox. Following this 10 -min exploration period, four groups received identical tone-shock conditioning in the startbox (refer to Table 1). The rat was placed in the startbox and the trapdoor released, dropping the subject to the grid flood. A barrier blocked entrance to the alley. The rat stayed in the startbox during nine tone-shock pairings, which were initiated by the experimenter at intervals of $60-70 \mathrm{sec}$. On each pairing, the 5-sec tone terminated simultaneously with onset of a $1-\sec 65-\mathrm{V}$ shock.

Groups TC-NPC and TC-SP were treated identically to those above except that shock was never administered during this phase.

Phase 3: Testing. After the final tone-conditioning trial, all subjects were removed from the startbox and given 30-60 sec in the goalbox, followed by three prepunishment trials. During these trials, the buzzer was absent and the rat had access to the alley and goalbox. The subject was placed on the trapdoor and dropped while facing the goalbox. This latter event initiated the tone, which terminated as the rat entered the goalbox. After $30 \mathrm{sec}$ in the goalbox, the animal was reinserted into the startbox for the next trial.

The three prepunishment trials were given so that all animals had the opportunity to at least partially learn the running response before receiving the appropriate punishment conditions. However, Kruger's (1974) data suggest that these trials are not a necessary condition for fear-motivated vicious-circle behavior.

Table 1

Experiment 1: Experimental Design

Classical Conditioning

\begin{tabular}{clccc} 
& & \multicolumn{2}{c}{ Classical Conditioning } & \multicolumn{2}{c}{ Testing Runway } \\
\cline { 2 - 5 } Group & \multicolumn{1}{c}{ Phase I } & Phase II & $\begin{array}{c}\text { Motivating } \\
\text { Stimulus }\end{array}$ & $\begin{array}{c}\text { Punishment } \\
\text { Condition }\end{array}$ \\
\hline TC-NPC & Buzzer-Shock Pairings & Tone & Tone & None \\
TC-SP & Buzzer-Shock Pairings & Tone & Tone & Buzzer \\
CS-NPC & Buzzer-Shock Pairings & Tone-Shock Pairings & Tone & None \\
CS-SP & Buzzer-Shock Pairings & Tone-Shock Pairings & Tone & Buzzer \\
CS-TSP & Buzzer-Shock Trace Conditioning & Tone-Shock Pairings & Tone & Buzzer \\
CS-RBC & Buzzer Presented Randomly in Relation to Shock & Tone-Shock Pairings & Tone & Buzzer \\
\hline
\end{tabular}


Following Trial 3, the subjects received the test trials. Conditions were identical to the prepunishment trials, except where indicated below (refer to Table 1): (1) Subjects in Groups CS-SP, CS-TSP. CS-RBC, and TC-SP were given the buzzer if they interrupted a photobeam located $24.5 \mathrm{in}$. $(62.3 \mathrm{~cm})$ from the beginning of the startbox. Entrance into the goalbox terminated the buzzer. (2) Groups CS-NPC and TC-NPC never received the buzzer during testing; i.e., test trials were identical to prepunishment trials.

Ninety-nine test trials were given, provided the subject continued to run. If the animal did not leave the prepunishment area within $30 \mathrm{sec}$ on two consecutive trials, testing ceased and scores of $30 \mathrm{sec}$ were assigned.

The treatment conditions of the three phases are conveniently summarized by group labels described below (also refer to Table 1).

For each group, the first term refers to the motivating condition during instrumental testing. That is, groups that receive a conditioned stimulus (tone) in the startbox and alley are designated by a "CS" as the first term, e.g., CS-NPC. The two groups that received the tone but no shock during tone conditioning (Phase 2) are controls for any possible aversive properties of this tone, since they also are presented with the tone during testing in the startbox and alley. These "tone control" groups are designated by a "TC" as the first term, e.g.. TC-NPC.

The second term of each group designation refers to the punishment condition during instrumental testing. The groups secondarily punished with a buzzer CS are designated "SP," whereas the group secondarily punished with a trace-conditioned buzzer is labeled "TSP." The group which is "punished" with a buzzer that was randomly presented in conjunction with a shock during Phase 2 is designated "RBC" (random buzzer control). Finally, two groups given stand ard classical conditioning during Phase 2, but receiving no stimulus contingent on running during testing, are given a second-term designation of NPC (no punishment control).

\section{Results and Discussion \\ Prepunishment Trials: Alley Speed}

Before punishment was introduced, the four CS groups had received equivalent tone-shock treatments, as well as an equal number of buzzer and shock presentations. An analysis of variance of median alley speed across the three prepunishment trials indicated no significant difference between the four CS groups $[F(3,28)=.50]$, hence, no sampling bias in their selection.

\section{Number of Subjects Meeting Extinction Criterion}

Rats in the TC groups, which received the tone without shock pairings, typically ran slowly or not at all and soon met the extinction criterion of two $30-\mathrm{sec}$ nonresponses. The median number of trials to extinction for Group TC-NPC was 6, for TC-SP, 4, and for all other groups, 99 . The number of subjects meeting the extinction criterion and the $\mathrm{n}$ for each group were Groups TC-NPC, 5/5; TC-SP, 4/5; CS-NPC. 1/8; CS-SP, 0/8; CS-TSP, 0/8; and CS-RBC, 1/8. Significantly more Group TC-NPC subjects met the extinction criterion than did CS-NPC rats (Fisher's exact probability test, $p=.01$ ). Although one rat in the TC-SP group ran to the 99-trial limit, this group was significantly less resistant to extinction than the CS-SP group (Fisher's exact probability test, p = .02 ). These two TC groups provide a baseline measure of running due to the tone and startbox cues alone (no history of pairing such cues with shock). They also allow us to evaluate the possibility of subjects running through secondary punishment on test trials and then continuing to run without prior conditioning of fear to the tone and startbox stimuli.

\section{Prepunishment Speed}

Mean prepunishment speed, the reciprocal of prepunishment time, was calculated across 11 blocks of nine test trials for Groups CS-SP, CS-TSP, CS-RBC, and CS-NPC. Analysis of variance revealed that the decline in speed over blocks of trials was significant $[F(10,280)=5.39, p<.001]$. However, no other effect was statistically significant. Trends in this speed measure were similar to those shown with alley speed.

\section{Alley Speed}

Figure 1 presents the mean alley speed (reciprocal of alley time) of four groups over 11 blocks of nine test trials. Analysis of variance revealed that the Groups effect was significant $[F(3,24)=4.96, p<.01]$ and the effect of Blocks $[F(10,280)=19.51, p<.001]$, but not the interaction.

Since there were no interactions between groups and blocks of trials, intergroup comparisons were made using means across all blocks of trials. As Figure 1 indicates, Groups CS-SP and CS-TSP ran considerably faster than the control groups, CS-NPC and CS-RBC. Duncan's new multiple range test showed that Group CS-SP was significantly faster than either Group CS-NPC $\left[\mathrm{D}_{\mathrm{R}}(28)=.256, \mathrm{p}<.01\right]$ or Group CS$\mathrm{RBC}\left[\mathrm{D}_{\mathrm{R}}(28)=.201, \mathrm{p}<.05\right]$.

Similarly, the trace-conditioned group (CS-TSP) ran reliably faster than either Group CS-NPC [DR $(28)$ $=.262, \mathrm{p}<.01]$ or Group CS-RBC $\left[\mathrm{D}_{\mathrm{R}}(28)=.207\right.$, $\mathrm{p}<.05]$.

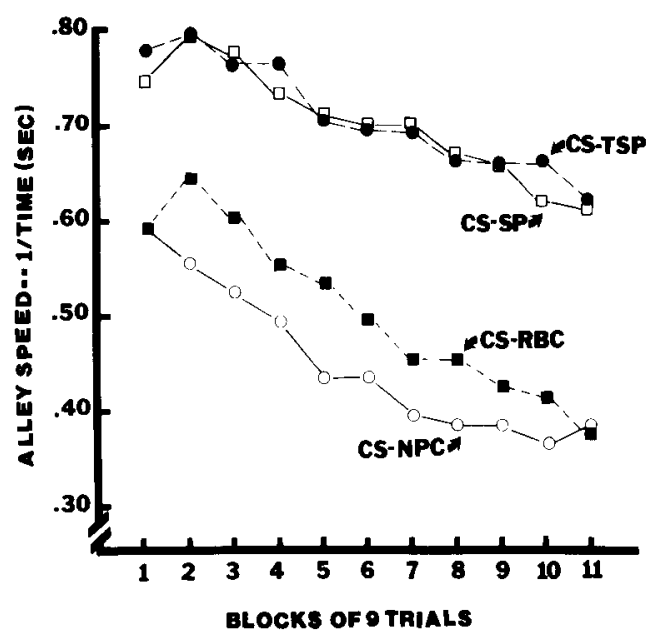

Figure 1. Mean alley speed for the four groups over 11 blocks of test trials. Group CS-SP received secondary punishment; Group CS-TSP received the trace-conditioned secondary punishment; Group CS-RBC was the random-buzzer control group; and Group CS-NPC was the nonpunished control group. 
A similar test comparing groups CS-SP and CS-TSP revealed a nonsignificant effect. The control groups, CS-RBC and CS-NPC, also did not differ significantly from each other.

The trace-conditioned group showed strong selfpunitive behavior equivalent to that obtained with delay conditioning (CS-SP). Results with short trace intervals in fear conditioning have been mixed (see review by McAllister \& McAllister, 1971). During trace conditioning, our subjects typically vocalized throughout the trace interval after three to five pairings.

We conclude that "all-secondary" vicious-circle behavior can be established through Pavlovian (delay and trace) conditioning.

\section{EXPERIMENT 2}

Experiment 1 provides substantial evidence that vicious-circle behavior can be established through the use of secondary motivation combined with secondary punishment. Experiment 2 was designed to examine the generality of this effect. In all relevant research on either secondary motivation or secondary punishment, the UCS has been electric shock. In Experiment 2, one of the UCSs was a drop into a water tank, whereas the other UCS remained as electric shock. Thus, the two CSs elicited fear based on two quite different aversive events.

Other modifications involved the use of a group given partial secondary punishment and a backwardconditioning control group.

\begin{abstract}
Method
Subjects

Twenty-four naive male Long-Evans hooded rats served as subjects. Fourteen rats were obtained from Charles River Breeding Lab, Inc., the other 10 rats from Blue Spruce Farms, Inc. As far as possible, rats of both strains were distributed equally across conditions. All animals were between 90 and 137 days old at the beginning of the experiment. Handling and housing conditions were identical to those of Experiment 1 .
\end{abstract}

\begin{abstract}
Apparatus
The apparatus consisted of a straight alley (described in Experiment 1) and a water-drop conditioning chamber. The latter was composed of a drop box, water tank, associated electronic equipment, and the same buzzer used in Experiment 1. The drop box had wooden sides, a hinged Plexiglas top and a hinged Masonite trapdoor, it measured $71 / 4 \times 31 / 4 \times 43 / 8 \mathrm{in}$. $(18.3 \times 8.3 \times 11 \mathrm{~cm})$. It was positioned over the water tank by means of three wooden horizontal supports that rested on the tank's rim. Mounted on one support was a small electric motor with a projecting arm that fitted beneath the trapdoor. Activating the motor released the trapdoor, dropping the rat into the water tank. The water tank was a 10-gal (42.3-liter) aquarium measuring $20 \times 10 \times 11^{3 / 4}$ in. $(50.8 \times 25.4 \times$ $29.9 \mathrm{~cm}$ ). It was filled with water at $23^{\circ} \mathrm{C}$ to a depth of $5 \frac{1}{2} \mathrm{in}$. $(13.3 \mathrm{~cm})$. The distance between the floor of the drop box and the surface of the water was $7-5 / 8$ in. $(19.4 \mathrm{~cm})$.

Other equipment employed was identical to that described in Experiment 1. The same was true for definitions of prepunishment time and alley time.
\end{abstract}

\section{Procedure}

Phase 1: Fear conditioning with buzzer. On Day 1, the subject was placed in the drop box for $10 \mathrm{~min}$ prior to conditioning. Each subject was randomly assigned to one of four groups $(n=6$ per group)-CS-SP100, CS-SP33, CS-SPO, and CS-BCC.

As in Experiment 1, the first term designates the motivating condition during instrumental testing; the second term identifies the secondary punishment condition. Thus, Groups SPO, SP33, and SP100 were secondarily punished on $0 \%, 33 \%$, or $100 \%$ of the instrumental test trials, respectively. Group CS-BCC was a backward conditioning control group.

The subject in the CS-SP100, CS-SP33, and CS-SPO groups were given a 3-sec buzzer while in the drop box. Concurrent with the offset of this buzzer, the trapdoor was released, dropping the subject: into the water. The experimenter immediately removed the rat from the water with a plastic scoop and returned it to the drop box. Nine conditioning trials were given, with an intertrial interval of $195 \mathrm{sec}$.

In the backward conditioning group (CS-BCC), the subject was dropped into the water with the release of the hinged floor and promptly returned to the drop box. Twenty seconds after the release of the hinged floor, a 3 -sec buzzer was presented. The intertrial interval was also $195 \mathrm{sec}$ and nine trials were given.

Phase 2: Tone conditioning. On Day 2, all groups in Experiment 2 received identical conditioning to that of the CS groups in Experiment 1, except that subjects in the second experiment received fewer pairings (five) of the tone with a lower intensity (55-V) shock.

Phase 3: Testing. The testing conditions were identical to those of the first experiment, except for the following modifications. During the test trials, Groups CS-SP100 and CS-BCC received the buzzer in the runway on $100 \%$ of the trials in which the subject interrupted the appropriate photobeam. Subjects in Group CS. SP33 received the runway buzzer on $33 \%$ of the trials in which they interrupted the photobeam, i.e., three randomly selected buzzer trials per nine trial blocks. Rats in Group CS-SPO never received the buzzer during testing.

\section{Results and Discussion \\ Prepunishment Trials: Alley Speed}

Before punishment was introduced, the four groups had received equivalent tone/water-drop treatments, as well as an equal number of buzzer and shock presentations. A Kruskal-Wallis one-way analysis of variance of median alley speed across the three prepunishment trials indicate no significant difference between the four groups $[H(3)=4.12, \mathrm{p}>.05]$, hence, no sampling bias in their selection.

\section{Number of Subjects Meeting Extinction Criterion}

The numbers of subjects meeting the extinction criterion for each group ( $n=6 /$ group) were as follows: CS-SP100 (0), CS-SP33 (1), CS-BCC (1), and CS-SPO (5). Comparisons of Group CS-SPO with the other three groups revealed that only Group CSSP100 showed significantly more resistance to extinction (Fisher's exact probability test, $\mathrm{p}=.05$ ).

\section{Prepunishment Speed}

Figure 2 shows the mean prepunishment speed for the four groups over blocks of test trials. An analysis of variance revealed that the effect of Groups was significant $[F(3,20)=3.26, p<.05]$. Speed decreased reliably across blocks of trials $[F(10,200)=$ $2.99, \mathrm{p}<.011$. The interaction effect was not significant.

A 3 by 11 analysis of variance across the dimension of percentage of secondary punishment compared Groups CS-SPO (0\%), CS-SP33 (33\%), and CS- 


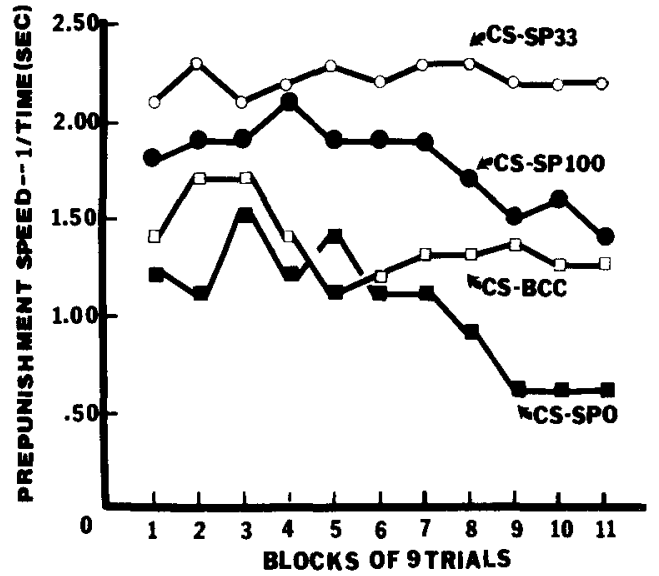

Figure 2. Mean speed in the prepunishment region for four groups over 11 blocks of test trials. Group CS-SP100 received secondary punishment on all trials and Group CS-SP33, on 33\% of the trials; Group CS-SPO was never punished; and Group CSBCC was a backward-conditioning control group.

SP100 $(100 \%)$ with respect to prepunishment speed across blocks. The effect of groups was significant $[F(2,15)=11.45, p<.001]$ and so was the effect of blocks $[\mathrm{F}(10,150)=17.29, \mathrm{p}<.001]$. The interaction was not significant.

Duncan's new multiple range test was used to analyze mean speed across all blocks of trials. The comparison between Group CS-SP100 and the backward conditioning control group failed to yield significant effect $\left[D_{R}(20)=.423, p>.05\right]$.

\section{Alley Speed}

Figure 3 presents alley speeds for the four groups over 11 blocks of nine test trials. Analysis of variance revealed a significant Groups effect $[F(3,20)=8.38$, $\mathrm{p}<.001]$. The significant effect for Blocks $[\mathrm{F}(10,200)$ $=13.96, \mathrm{p}<.001]$, but not for the interactions, reflects the general decline in speed across blocks of trials.

An analysis across the dimension of percentage of secondary punishment $(0 \%, 33 \%$, and $100 \%)$ compared Groups CS-SPO, CS-SP33, and CS-SP100. The effect of groups was statistically significant $[F(2,15)=11.45, \mathrm{p}<.001]$. Again, the effect of blocks, but not the interaction, was significant.

As Figure 3 indicates, Group CS-SP100 ran faster than the backwards-conditioning control group, CS-BCC. A Duncan's new multiple range test of mean speeds across blocks revealed this difference to be significant $\left[D_{R}(20)=.458, p<.01\right]$. Also, Group CS$\mathrm{BCC}$ ran significantly faster than the nonpunished group, CS-SPO $\left[\mathrm{D}_{\mathrm{R}}(20)=.260, \mathrm{p}<.05\right]$.

As in Experiment 1, self-punitive running was established through secondary punishment of a response motivated by conditioned fear. However, in the present experiment the sources of fear for the motivational and punitive stimuli were based on two quite different aversive events.

Our results indicate that the effects of partial secondary punishment were about equivalent to those of continuous punishment. These data, obtained through our buzzer/water-drop conditioning procedure, are different from Bender's (1969) results based on the more typical CS-shock procedure. She found that $33 \%$ secondary punishment yielded slower performance than $100 \%$. Several experiments using shock punishment, however, have found partial punishment of $20 \%-50 \%$ to yield self-punitive running equivalent to $100 \%$ (see review by Melvin, 1971).

\section{GENERAL DISCUSSION}

The results of Experiments 1 and 2 indicate that self-punitive behavior can be established by combining secondary sources of motivation and punishment. This "all-secondary" vicious-circle behavior seems to be a robust phenomenon, because (a) it is found even when the conditioned fear used as the motivator is based on a qualitatively different aversive event (electric shock) from that event used to establish secondary punishment (water drop), and (b) it is seen with secondary punishment established through a trace-conditioning procedure or applied on a partial punishment schedule.

The Mowrer-Brown fear hypothesis (Brown, 1969; Melvin, 1971) holds that during extinction (or testing), alley cues are paired with shock punishment. Since the startbox and alley are similar, punishmentgenerated conditioned fear generalizes to the start area, summating with fear conditioned in this area during training, to maintain the running response. In our study, the punishment is secondary. Thus, we must adopt a logical extension of the Mowrer-Brown hypothesis, i.e., that here it is the generalization of

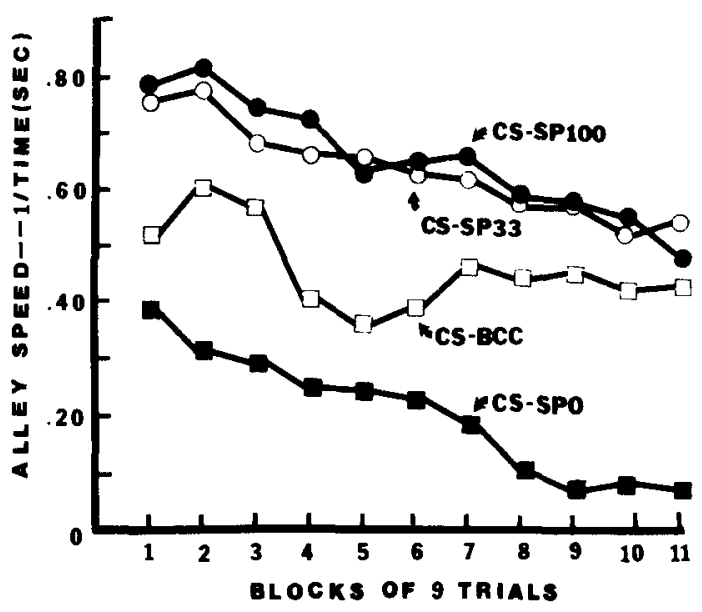

Figure 3. Mean alley speed for the four groups over 11 blocks of test trials. Group designations are the same as in Figure 2. 
higher order fear conditioning that maintains running. The gradual decline in self-punitive running across trials is consistent with such an assumption.

A number of theorists have assigned some role to shock-elicited motor responses in their accounts of the vicious-circle phenomenon (e.g.. Brown, 1969; Delude, 1969; Fowler, 1971; Melvin, 1971). For example, Delude assigns a major role to shock-elicited running, holding that shock compels the animal to remove itself from the electrified alley section during punishment extinction. Other theorists, such as Brown (1969), have noted that the shock tends to lose its power to evoke withdrawal reactions to the degree it becomes a conditioned stimulus for forward locomotion. Results from our shock-free instrumental paradigm show that the response-eliciting effects of electric shock play no necessary role in vicious-circle behavior. This is not to say that these notions may not have some explanatory role when shock is used during the instrumental response.

Prior studies of secondary punishment or motivation have found that the principles of Pavlovian conditioning govern instrumental self-punitive running. Galvani (1969) found that secondarily motivated vicious-circle behavior was enhanced as a function of number of CS-UCS pairings. In a similar paradigm, Kruger (1974) found that self-punitive running increased as a function of UCS intensity. Increasing UCS intensity also led to faster running when secondary punishment was used (Saunders, 1971). Furthermore, secondary punishment has resulted in a gradual decline in speed in the punished groups, relative to primary (shock) punishment (Bender, 1969; Saunders, 1974). Again, this finding is consistent with the principles of Pavlovian conditioning; i.e., fear of the CS should gradually extinguish and thus the animal becomes slower.

In our experiment, the punished groups all show a gradual decline in response strength. However, the slope of the curves is steeper in Experiment 2 (Groups CS-SP100 and CS-SP33) than it is in Experiment 1 (Groups CS-SP100 and CS-TSP). This difference may be due to the lower UCS intensity and fewer tone-UCS pairings used to establish motivation in the second experiment. Data from the nonpunished control groups (CS-NPC and CS-SPO) across the two experiments supports this conjecture. That is, the CS-SPO group of Experiment 2, which received lower shock intensity and fewer tone-shock pairings, extinguished rapidly relative to its counterpart in Experiment 1 . Thus, it appears that the lower motivation of the punished rats in Experiment 2 (rather than any lesser punishment intensity) led to a steeper decline in their performance relative to the punished animals of Experiment 1. Again, this outcome is consistent with the principles of classical fear conditioning as applied to instrumental self-punitive running.

\section{REFERENCES}

BrNDER. L. Secondaly punishment and self-punitive behavior in the rat. Journal of Comparative and Physiological Psychology. 1969. 69. 261-266.

Brister. P. D. Breaking the vicions circle: An examination of the efficacy of several procedures. Unpublished doctoral dissertation, University of Alabanta, 197h.

Brown. J. S. Factors affecting self-punitive locomotor behavior. In B. A. Campbell \& R. M. (hurch (Eds.). Punishment and aversive beharior. New York: Appleton-Century-Crofts. 1969.

Brown, J. S., Martin, R. C.. \& Morrow, M. W. Self-punitive behavior in the rat: Facilitative effects of punishment on resistance to extinction. Journal of Comparative and Physiological Psychology. 1964, 57, 127-133.

Delude. L. A. The vicious circle phenomenon: A result of measurement artifact. Journal of Comparative and Physiological Psychology, 1969, 69, 246-252.

FowLER. H. Suppression and facilitation by response contingent shock. In F. R. Brush (Ed.), Aversive conditioning and learning. New York: Academic Press, 1971.

(jalvans. P. F. Self-punitive behavior as a function of number of prior fear-conditioning trials. Journal of Comparative and Physiological Psychology. 1969, 68, 359-363.

Kruger, B. M. Self-punitive running in the rat following start box fear conditioning: Shock intensity effects. Joumal of Comparative and Physiological Psychology. 1974, 87, 555-562.

MCAllister, W. R., \& MCAllister, D. E. Behavioral measurement of conditioned fear. In F. R. Brush (Ed.). Aversive conditioning and learning. New York: Academic Press, 1971.

Melvin, K. B. Vicious circle behavior. In H. D. Kimmel (Ed.), Experimental psychopathology: Recent research and theory. New York: Academic Press, 1971.

Meivin, K. B., Athey, G. I., JR..\& Heasley, F. H. Effects of duration and delay of shock on self-punitive behavior in the rat. Psychological Reports, 1965, 17, 107-112.

Meivin, K. B., \& Martin, R. C. Facilitative effects of two modes of punishment on resistance to extinction. Journal of Compararive and Physiological Psychology. 1966. 62, 491-494.

Melvin, K. B., \& Stenmark, D. E. Facilitative effects of punish. ment on the establishment of a fear motivated response. Journal of Comparative and Physiological Psychology, 1968, 65, 517-519.

Miller, H. L., House, N. H., III, \& Melvin, K. B. Vicious circle behavior in humans through secondary punishment. Psychological Record, 1978, 28, 231-235.

SAUNDERS, T. R., JR. Effects of US intensity and number of CS-US pairings on the maintenance of vicious circle behavior by secondary punishment. Journal of Comparative and Physiological Psychology, 1974, 86, 535-542.

(Received for publication April 11, 1978; revision accepted August 21, 1978.) 